\title{
The human lateral tuberal nucleus: Immunohistochemical characterization and analogy to the rodent PV1-nucleus
}

\author{
Anna T. Gerig, Marco R. Celio* \\ Anatomy Unit, University of Fribourg, Rte Albert Gockel 1, CH-1700 Fribourg, Switzerland
}

\begin{abstract}
A B S T R A C T
The lateral tuberal nucleus (LTN) is a hypothalamic region that has been identified with certainty only in humans and primates. It is composed of three small round globular units which protrude the basal surface of the brain along the optic tract. The function of the LTN is unknown. Recently, a tiny, parvalbumin-positive (PV1) nucleus was detected in the lateral hypothalamus of rodents. Like the human LTN, the rodent PV1-nucleus is subdivided into three units and lies along the optic tract. To ascertain whether the human LTN and the rodent PV1-nucleus could be considered as homologous structures not only based on their topographic location but also because of their neurochemical characteristics, we subjected tissue samples from humans, rats and mice to immunohistochemical analysis for a panel of neural markers. The human LTN was intensely immunoreactive for somatostatin and FF1, but only weakly so or not at all for parvalbumin, calbindin and calretinin. The rodent PV1nucleus was intensely immunoreactive for parvalbumin but was not immunoreactive for either somatostatin, a surrogate for human FF1, calbindin or calretinin. Hence, using these neural markers, it was not possible to demonstrate a neurochemical homology between the human LTN and the rodent PV1-nucleus.
\end{abstract}

\section{Introduction}

The lateral tuberal nucleus (LTN) has not yet been assigned a clear function in primates. It is composed of three subnuclei, which lie along the optic tract and often bulge from the lower surface of the hypothalamus. In humans the LTN is immunoreactive for somatostatin, orexin A and hFF1 and undergoes marked changes in patients suffering from either Huntington's (Hofman, 1997; Timmers et al., 1996), Pick's (Braak and Braak, 1998) or the argyrophilic grain disease (Schultz et al., 1998).

It is a paradigm of neuroscience that the functional analysis of human brain areas is promoted and facilitated if homologous structures are known to exist in lower mammals. But in the case of the LTN, only primates appear to possess a similar structure (Fujii, 1982; Narkiewicy et al., 1994; Goncharuk et al., 2004). The occurrence of an LTN in rodents is controversial. Recently, however, a tiny, parvalbumin-positive (PV1) nucleus has been identified in the lateral hypothalamus of rodents. It is subdivided into three portions, lies along the optic tract and bulges from the basal surface of the hypothalamus (Celio, 1990; Celio and Saper, 1999, not published results). From its topography and organization, it is believed to be a homologue of the human LTN. This contention would be supported if the rodent and human counterparts were found to have similar neurochemical

\footnotetext{
* Corresponding author. Fax: +41 263009732.

E-mail addresses: ankhemet@bluemail.ch (A.T. Gerig), marco.celio@unifr.ch (M.R. Celio).

Abbreviations: LTN, lateral tuberal nucleus; PV1, parvalbumin-positive nucleus in the lateral hypothalamus of rodents
} 
compositions. In the present study, we compare the distribution of the calcium-binding proteins, neuromodulators and neurotransmitters in the human LTN and the rodent PV1-nucleus, with a view to identifying common chemical markers.

\section{Results}

The human lateral tuberal nucleus (LTN) is located within the most lateral aspect of the hypothalamus. It consists of three discrete spherical entities, which are aligned along the optic tract and protrude from the basal surface of the hypothalamus (Figs. 1A, B). The LTN is subject to variations between individuals. Indeed, the protuberances are not recognizable in all brains.

In brain sections stained with Nissl's reagent, each component of the LTN measures approximately $1.5 \mathrm{~mm}$ in diameter, although the middle one tends to be slightly smaller than the other two (Fig. 2A). The LTN is bordered laterally by the optic tract, dorsolaterally by the internal capsule, medially
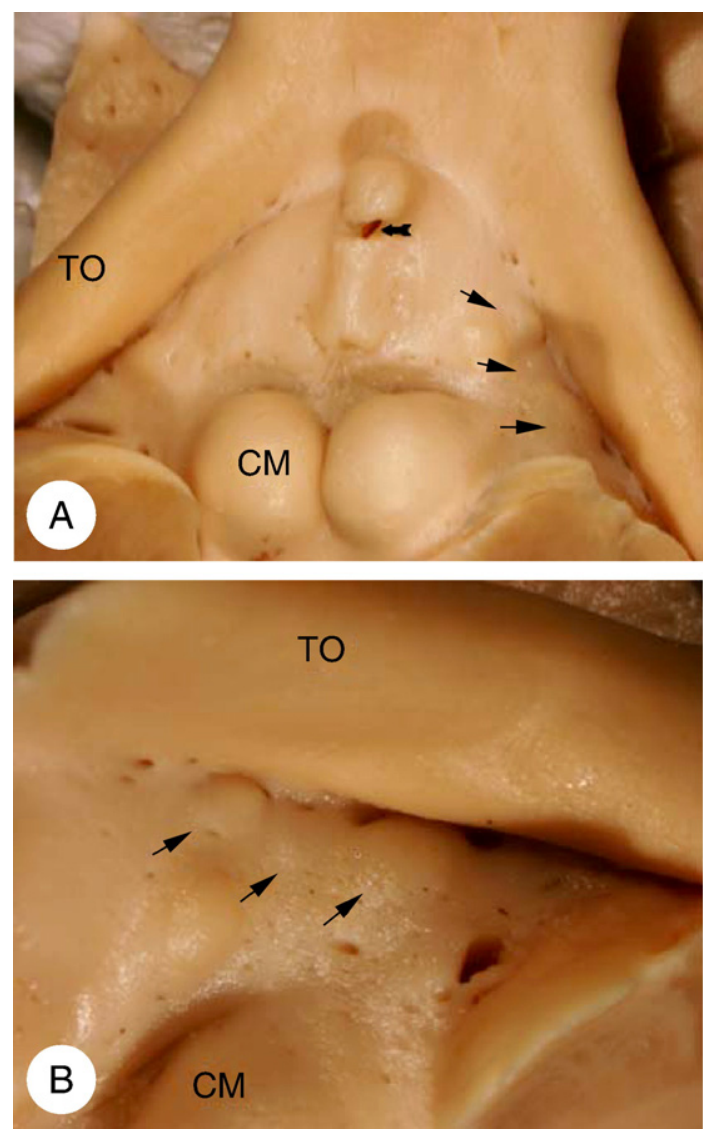

Fig. 1 - Macroscopic views of the basal hypothalamus in a human brain. (A) The slender point to the three protuberances of the LTN, which lie between the corpora mamillaria (CM), the tractus opticus (TO) and the pituitary stalk (thick arrow: infundibulum). (B) Higher-magnification view of panel A turned $90^{\circ}$ counterclockwise, revealing the bulging nature of the three LTN units (arrows). Magnification: $\times 5$.
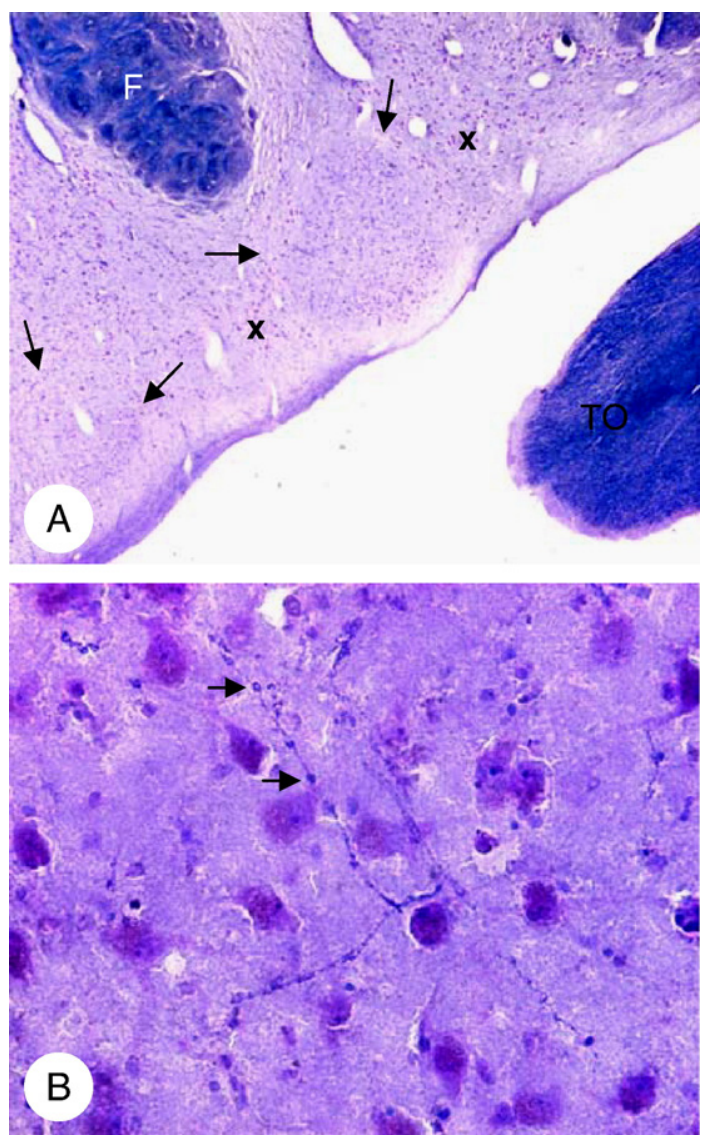

Fig. 2 - Light micrographs of the human LTN stained with Cresyl violet-Luxol fast blue. (A) Low-magnification view of the LTN in which two of the three globose units are indicated (arrows). Each subnucleus is encapsulated by a fibrous network ( $x$ ), which is surrounded by the large cells of the tuberomamillary nucleus. F: Fornix; TO: Tractus opticus. Magnification: $\times 40$. (B) Higher-magnification view of panel A revealing the presence of nerve-fibre boutons (arrows) and cell bodies of similar diameter. Magnification: $\times \mathbf{4 0 0}$.

by the descending fornix, mediocaudally by the mamillary body and ventrally by the pia mater (Kremer, 1992). Staining with Cresyl violet-Luxol fast blue reveals the presence of medium-sized, multipolar neurons (Fig. 2B) (Braak and Braak, 1992). A distinct compartmentalization of centrally and peripherally located neurons is apparent. But within each of three regions, the cells are distributed homogeneously (Le Gros Clark et al., 1938). The subnuclei are traversed by relatively few myelinated fibres (Fig. 2B). Each unit of the LTN is encapsulated by a loose fibrous network, which is surrounded by the large cells of the tuberomamillary nucleus.

The immunohistochemical analysis for various markers (Table 2) reveals no correspondence between the chemoarchitectonic of the human LTN and the rodent PV1-nucleus. In human brain sections treated with antibodies against parvalbumin (Figs. 3A, B), the LTN is barely distinguishable from the surrounding tissue. And it is immunoreactive for neither calbindin (Figs. 3C, D) nor calretinin (Figs. 3E, F). However, it is intensely labelled with antibodies against 

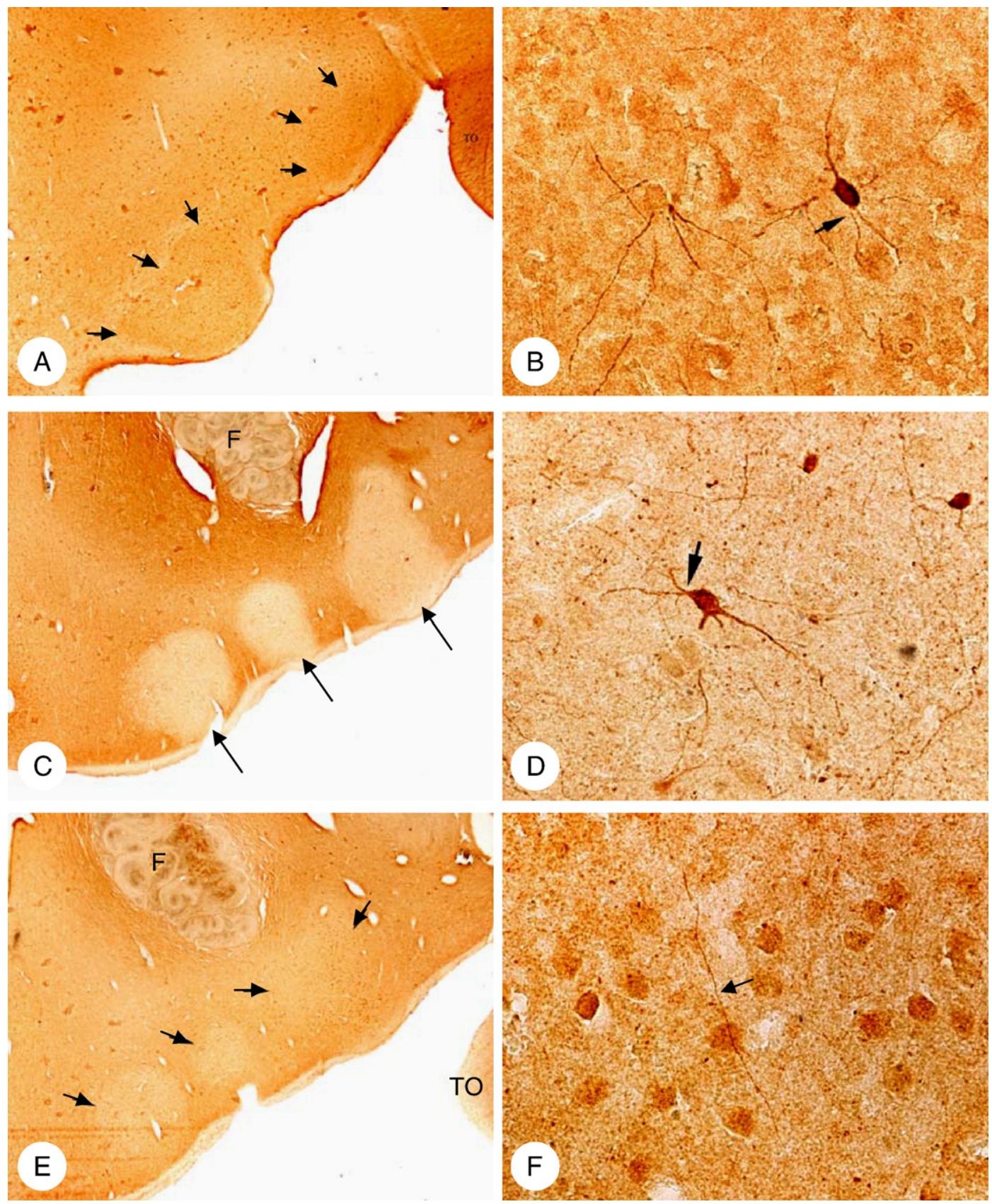

Fig. 3 - Light micrographs of the humans LTN after treatment with antibodies against parvalbumin (A, B), calbindin D-28k (C, D) and calretinin (E, F). (A) Low magnification view revealing weak immunoreactivity for parvalbumin within the LTN (arrows delimit the boundaries of two subunits). Magnification: $\times 40$. (B) Higher magnification view of panel A in which exceptionally a rare PV-immunoreactive cells is depicted (arrow). Magnification: $\times 400$. (C) Low magnification view of the LTN revealing the selective absence of immunoreactivity for calbindin D-28k in the three round subnuclei (arrows). F: Fornix. Magnification: $\times 40$. (D) Higher-magnification view of panel C revealing the presence of a few intensely labelled multipolar cells. The course followed by both axons and dendrites (arrow) can be followed over relatively long distance by virtue of their immunoreactivity.

Magnification: $\times 400$. (E) Low-magnification view of the LTN (arrows) revealing the selective absence of immunoreactivity for calretinin (arrows). F: Fornix. Magnification: $\times 40$. (F) Higher-magnification view of panel E revealing no more than a background immunostaining of the cell bodies. However, some of the traversing fibres are labelled (arrow). Magnification: $\times 400$.

somatostatin (Figs. 4A, B) and the neuropeptide FF receptor FF1 (Figs. 4C, D). In highly magnified images, fibres (probably axons) are stained with all markers. Along their trajectory some positively stained varicosities can be discerned with some markers.
In mice and rats, brain sections treated with antibodies against parvalbumin disclose the presence of labelled neurones and axons within the PV1-nucleus (Figs. 5A and B). With all other antibodies used in this study, the PV1-nucleus does not manifest immunoreactivities, and it can be distinguished 

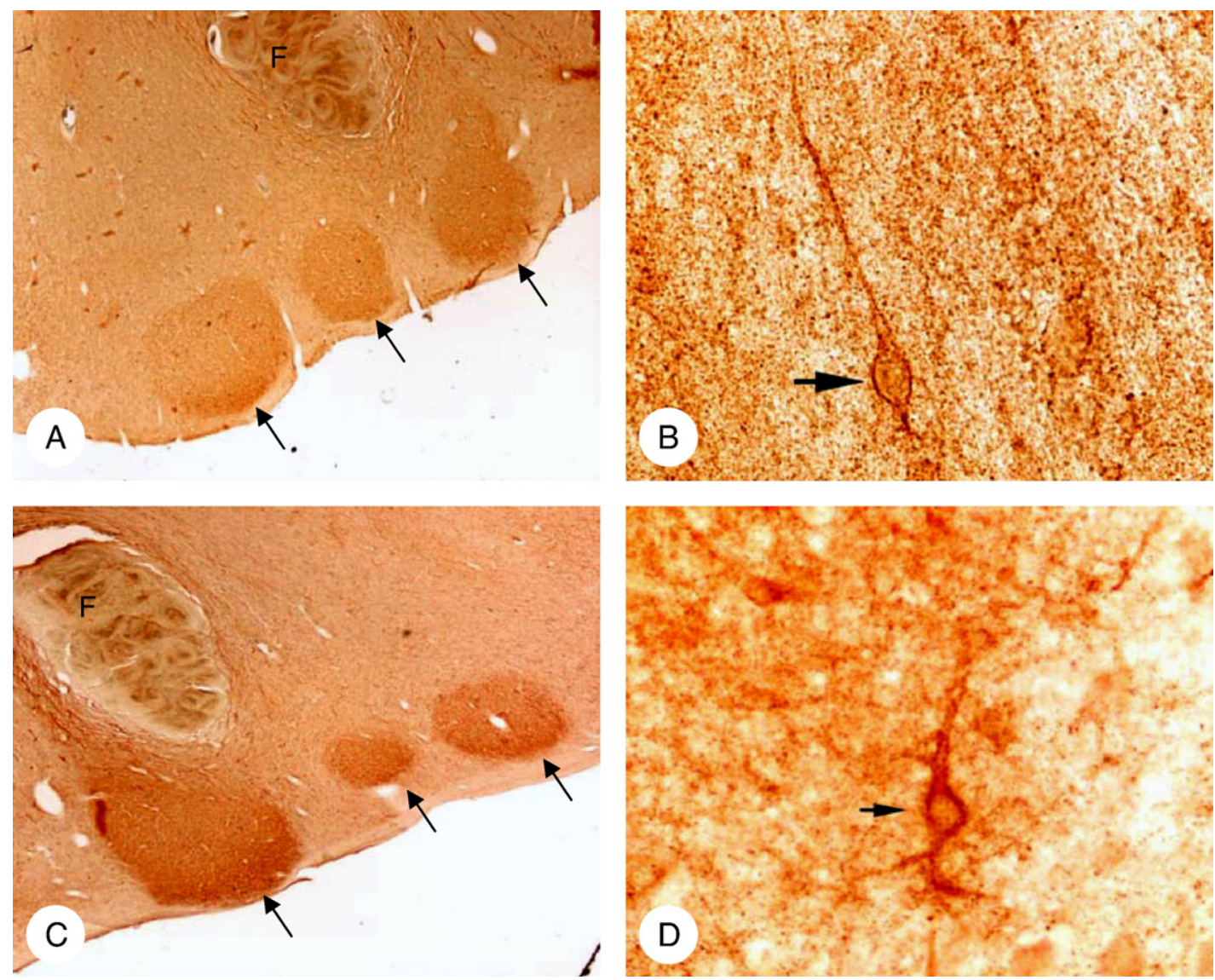

Fig. 4 - Light micrographs of the human LTN after treatment with antibodies against somatostatin 309 (A, B) and human FF1 (C, D). (A) Low-magnification view revealing strong immunoreactivity for somatostatin within the three subnuclei of the LTN (arrow), and moderate or absent for the adjacent tissue. F: Fornix. Magnification: $\times 40$. (B) Higher-magnification view of panel A depicting a cell body whose surface is adumbrated by abutting immunoreactive nerve fibres (arrow). The tissue is rich in labelled fibres and terminals. Magnification: $\times 400$. (C) Low-magnification view of the LTN revealing intense immunoreactivity for FF1 in the three LTN-subnuclei (arrows). F: Fornix. Magnification: $\times 40$. (D) Higher-magnification view of panel C revealing the abundance of immunoreactive nerve fibres and terminals. Several fibres are here seen to align the surface of a cell body (arrow). Magnification: $\times \mathbf{4 0 0}$.

from the surrounding tissue as negative image (data not shown).

\section{Discussion}

In the present study, we wished to ascertain whether the human LTN and the rodent PV1-nucleus could be considered as homologues based on their neurochemical characteristics. To this end, the structures were subjected to an immunohistochemical analysis for a panel of reference neural markers. Somatostatin, and FF1 are recognized markers if the human LTN (Timmers et al., 1996; Goncharuk et al., 2004), whereas the calcium-binding protein parvalbumin is the typical marker of the rodent PV1-nucleus (hence its name) (Celio, 1990).

Specimens were subjected to an immunohistochemical analysis not only for these markers but also for two other calcium-binding proteins, namely calretinin and calbindin, which also occur in the hypothalamus.

The human LTN and the rodent PV1-nucleus did not stain alike this panel of markers. Nevertheless, subtle similarities could be discerned. As anticipated, the human LTN manifested intense immunoreactivity for somatostatin and FF1 (only fibres). The rodent PV1-nucleus did not stain for these markers. Similarly discrepant findings in phylogeny have been reported for the corticotropin-releasing factors, the muscarinic cholinergic receptor and GABA, each of which are expressed in regions of the human brain but not in the rodent (Pelletier et al., 1983; Millan et al., 1986; De Souza et al., 1985; Cortes et al., 1986; Trottier et al., 2002; Sakaue et al., 1988; Tappaz et al., 1977). Neither the human LTN nor the rodent PV1-nucleus manifested immunoreactivity for either calbindin or calretinin. But in each species, the surrounding tissue was labeled. The nuclei thereby appeared in negative relief. And in rodents, the same negative imaging of the PV1-nucleus was observed using a surrogate antibody for human FF1 (see Table 2).

Although the human LTN and the rodent PV1-nucleus share a common topographic location within the hypothalamus, they differ for these neurochemical markers. This paradox may be explained by phylogenetic differences in the connections and functions of these two nuclei. With respect to 

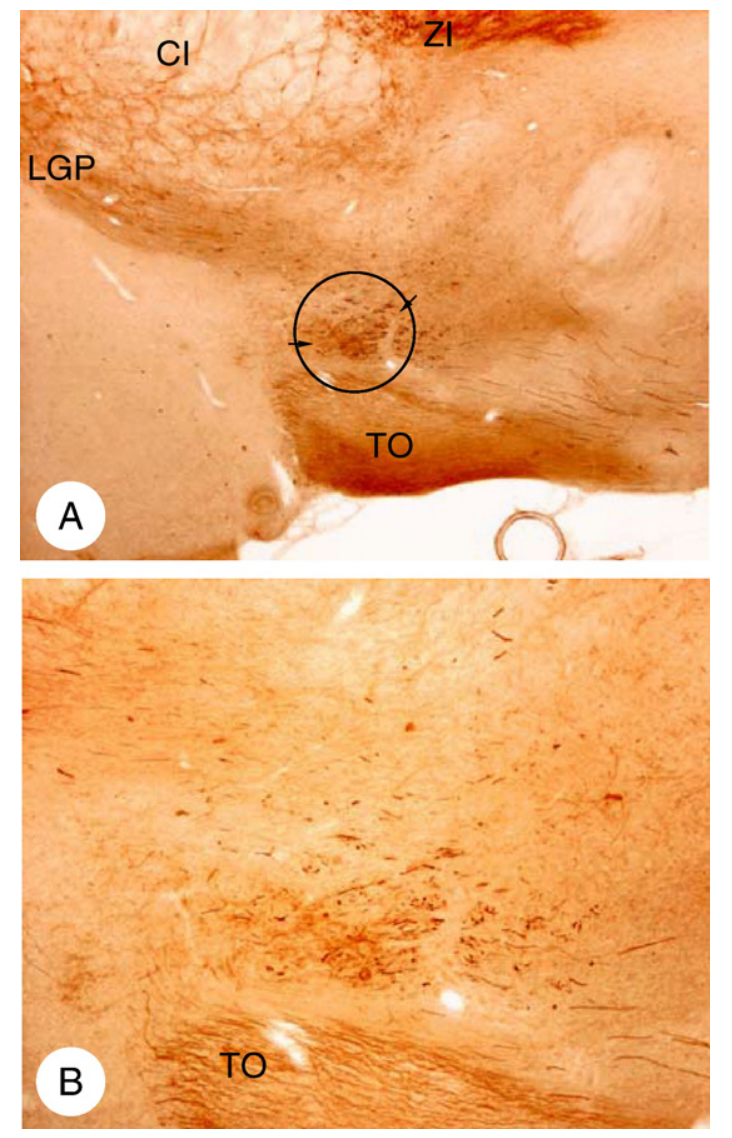

Fig. 5 - Light micrographs of the rat PV-nucleus after treatment with antibodies against parvalbumin (A, B) and calretinin (C, D). (A) Low-magnification view revealing intense immunoreactivity for parvalbumin within the PV1 nucleus (circled; lateral borders indicated by arrows). LGP: lateral globus pallidus; IC: internal capsule, ZI: zona incerta, TO: tractus opticus. Magnification: $\times \mathbf{4 0}$. (B) Higher-magnification view of panel A depicting the PV-nucleus in more detail. TO: tractus opticus. Magnification: $\times \mathbf{4 0 0}$.

calcium-binding proteins, differences between species are not uncommon. For instance, CA1 pyramidal neurons express calbindin $\mathrm{D}-28 \mathrm{k}$ in the rat, but not in either the human or the rabbit. Similarly, many thalamic nuclei express calbindin D-28k and parvalbumin in monkeys, but not in rats (Baimbridge et al., 1992).

Likewise, a quantitative comparison of the basal ganglia in the rats, monkeys and humans has revealed marked anatomical and neurochemical differences between these species (Hardman et al., 2002).

Although the function of the LTN is unknown, several hypotheses have been proposed based on its neurochemical composition in humans. The presence of somatostatin and of the neuropeptide FF receptor FF1 let to speculations that it might be involved in the regulation of food intake and in the homeostasis of the neuroendocrine system (Timmers et al., 1996; Goncharuk et al., 2004; Dockray, 2004; Nicklous and Simansky, 2003).

In patient suffering from Huntington's disease, the LTN incurs a substantial loss of cells (Kremer et al., 1991). In individuals with either Parkinson's or Alzheimer's disease, the number of cells does not change, but their characteristics do: they undergo cytoskeletal alterations and manifest cytoplasmatic inclusions such as Levy bodies (Hofman, 1997; Braak and Braak, 1998; Kremer, 1992; Kremer et al., 1990; Kremer and Bots, 1993). The fact that patients with neurodegenerative disease often suffer from cachexia and sleep disorders during the later stages of their disease (Kremer, 1992; Braak and Braak, 1992; Morton et al., 2005), supports the contention that the human LTN may be involved in the regulation of food intake and of the sleep-wake cycle.

Notwithstanding the topographic and morphologic analogies between the human LTN and the rodent PV1-nucleus, these structures do not express the same panel of neurochemical markers. Further experiments using more sophisticated techniques like proteomics and gene-arrays must now be conducted to establish whether these regions can be considered as homologues in a more subtle neurochemical respect.

\section{Experimental procedures}

\subsection{Human brain material and tissue treatment}

Ten human brains, which had been fixed in 10\% buffered formalin, were used for this study. The age and gender of the donors, as well as the cause of their death, are summarized in Table 1.

For cryoprotection, a single tissue block embracing the entire hypothalamus was removed and immersed in $0.1 \mathrm{M}$ Tris-buffered saline (TBS, pH 7.3) containing $18 \%$ sucrose and $0.02 \mathrm{M}$ sodium azide. When the tissue had become fully impregnate with sucrose, it was frozen and cut into $40-\mu \mathrm{m}$ thick slices on a Frigomobile (Reichert-Jung, Model 1206). The frozen tissue sections were maintained in 0.1 M TBS containing $0.01 \mathrm{M}$ sodium azide.

\subsection{Rat brain material and tissue treatment}

The brains of 8 male rats (300 g) and mice (50 g) were used for this study. The animal were anesthetized with Eutha 77

\begin{tabular}{|c|c|c|c|}
\hline $\begin{array}{l}\text { Case } \\
\text { number }\end{array}$ & $\begin{array}{c}\text { Age } \\
\text { (years) }\end{array}$ & Gender & Cause of death \\
\hline 223.SN.99 & 78 & Female & Myocardial infarction \\
\hline $171 \mathrm{SN} 98$ & 82 & Male & $\begin{array}{l}\text { Lung embolism, adenocarcinoma } \\
\text { of the colon }\end{array}$ \\
\hline 249.SN.99 & 55 & Male & Myocardial infarction \\
\hline 20.SN.00 & 78 & Male & Dissection of aorta \\
\hline 219.SN.99 & 75 & Male & Prostate cancer with metastases \\
\hline 196.SN.99 & 83 & Male & Myocardial infarction \\
\hline SN99-163 & 47 & Male & $\begin{array}{l}\text { Heart disease and renal } \\
\text { insufficiency }\end{array}$ \\
\hline 244.SN.99 & 69 & Female & Lung embolism \\
\hline 29 SN/99 & 83 & Female & Heart disease \\
\hline 252.SN.99 & 89 & Female & Ruptured aneurysm of the aorta \\
\hline
\end{tabular}

The hypothalamus was removed from the brains of these 4 female and 6 male cadavers, which were undergoing routine autopsies. 


\begin{tabular}{|c|c|c|c|c|c|}
\hline Antibody & Antigen & Source & $\begin{array}{l}\text { Dilution } \\
\text { human brain }\end{array}$ & $\begin{array}{l}\text { Dilution rat/ } \\
\text { mouse brain }\end{array}$ & $\begin{array}{l}\text { Characterized } \\
\text { in publication }\end{array}$ \\
\hline Calbindin D-28k & Recombinant rat calbindin & $\begin{array}{l}\text { Swant, Bellinzona, } \\
\text { Switzerland }\end{array}$ & $1: 2000$ & $1: 2000$ & $a$ \\
\hline Calretinin $7699 / 4$ & Recombinant human calretinin & $\begin{array}{l}\text { Swant, Bellinzona, } \\
\text { Switzerland }\end{array}$ & 1:5000 & 1:5000 & a \\
\hline Parvalbumin 4064 & Rat muscle parvalbumin & $\begin{array}{l}\text { Swant, Bellinzona, } \\
\text { Switzerland }\end{array}$ & 1:5000 & 1:5000 & a \\
\hline Somatostatin 309 & $\begin{array}{l}\text { Peptides } 1-28 \text { of rabbit } \\
\text { somatostatin }\end{array}$ & $\begin{array}{l}\text { Dr. R. Benoit, Salk } \\
\text { Institute, La Jolla }\end{array}$ & $1: 5000$ & $1: 5000$ & Benoit et al., 1982 \\
\hline Human FF1 & RFamide (FARP) receptor FF1 & $\begin{array}{l}\text { Dr. Zhizhen Zheng, } \\
\text { Merck Research } \\
\text { Laboratoires }\end{array}$ & $1: 2000$ & - & Goncharuk et al., 2004 \\
\hline $\begin{array}{l}\text { RF-amide-like peptide } \\
\text { (used in rodents } \\
\text { as a surrogate antibody } \\
\text { for human FF1) }\end{array}$ & Phe-Met-Arg Phe- $\mathrm{NH}_{2}$ & $\begin{array}{l}\text { Novus Biologicals, } \\
\text { Littletown, USA }\end{array}$ & - & $1: 20000$ & a \\
\hline
\end{tabular}

a Characterized by the commercial source. For the first three, antibody absorption experiments to control the specificity of staining were routinely performed.

(sodium phenobarbital), and in this state were perfused transcardially, first with $0.1 \mathrm{mM}$ phosphate-buffered saline, and then with $4 \%$ paraformaldehyde (in $0.1 \mathrm{mM}$ phosphate buffer saline, $\mathrm{pH}$ 7.3) for $10 \mathrm{~min}$.

The brains were excised and immersed in $0.1 \mathrm{M}$ TBS containing $18 \%$ sucrose and $0.02 \mathrm{M}$ sodium azide. Thereafter, the tissue was frozen, sectioned and stored as described above for human material.

\subsection{Immunohistochemistry}

Sections of human and rodent brains were treated in parallel according to the following protocol:

1) Pretreatment with a methanolic solution of hydrogen peroxide (50:1) for $20 \mathrm{~min}$ at ambient temperature to block the endogenous peroxidase activity;

2) rinsing in $0.1 \mathrm{M} \mathrm{TBS}(\mathrm{pH} 7.3)$;

3) steam-pressure pretreatment with $10 \mathrm{mM}$ citric buffer for $4 \mathrm{~min}$, followed by rinsing in tap water for $5 \mathrm{~min}$;

4) one 5-min wash in 0.1 M TBS;

5) incubation with primary antibodies (see Table 2), which was diluted in 0.1 M TBS ( $\mathrm{pH} 7.3$ ) containing $1 \%$ Triton $\mathrm{X}$ 100 and $10 \%$ bovine serum albumin, for 3 days at $4{ }^{\circ} \mathrm{C}$;

6) three 5-min rinses in $0.1 \mathrm{M}$ TBS;

7) incubation with biotinylated polyclonal goat anti-rabbit IgG for 2 hours at $37^{\circ} \mathrm{C}$ in a humidified atmosphere;

8) three 5-min rinses in 0.1 M TBS;

9) incubation with the avidin-peroxidase complex for $2 \mathrm{~h}$ at $37^{\circ} \mathrm{C}$ in a humidified atmosphere;

10) three 5 -min rinses in $0.1 \mathrm{M}$ TBS;

11) incubation in $\mathrm{DAB}$ (3,3-diaminobenzidine) containing hydrogen peroxide for $10 \mathrm{~min}$;

12) two 5 -min rinses in $0.1 \mathrm{M} \mathrm{TBS}$;

13) dehydration in $70 \%$ ( $5 \mathrm{~min}), 94 \%$ ( $5 \mathrm{~min}$ ) and $100 \%$ ethanol (10 min, with a change of medium halfway), clearance in xylene (10 min, with a change of medium halfway) and mounting in Entellan.

\subsection{Antibodies}

The antibodies used in this study, as well as their sources, are described in Table 2.

\subsection{Image processing}

Macroscopic images of the human brain were acquired digitally using a Nikon SMZ1000 instrument equipped with a Nikon digital camera DXM1200. Microscopic images of the slices were taken with the same Nikon camera using a Nikon Eclipse E400 microscope.

\section{Acknowledgments}

We would like to thank Prof. Robert Janzer (Neuropathology Department, University of Lausanne) for kindly supplying the human brains, Drs. R. Benoit and Zhizhen Zeng for their gifts of the somatostatin 28, respectively, the human FF1-antiserum, Mrs Brigitte Belser for her assistance with the immunohistochemical analysis, and Mrs Ceri England for her precious help in writing the manuscript.

\section{R E F EREN C E S}

Baimbridge, K.G., Celio, M.R., Rogers, J.H., 1992. Calcium-binding proteins in the rat nervous system. Trends Neurosci. 15 (8), 303-308.

Benoit, R., Ling, N., Bakhit, C., Morrison, J.H., Alford, B., Guillemin, R., 1982. Somatostatin-28(1-12)-like immunoreactivity in the rat. Endocrinology 111 (6), 2145-2149.

Braak, H., Braak, E., 1992. Anatomy of the human hypothalamus (chiasmatic and tuberal region). Prog. Brain Res. 93, 3-16.

Braak, H., Braak, E., 1998. Pick's disease: cytoskeletal changes in the hypothalamic lateral tuberal nucleus. Brain Res. 802 (1-2), 119-124. 
Celio, M.R., 1990. Calbindin D-28k and parvalbumin in the rat nervous system. Neuroscience 35, 375-475.

Celio, M.R., Saper, C.B., 1999. The parvalbumin positive nucleus of the rat lateral hypothalamus. Abstr. - Soc. Neurosci. 25, 1902 (Part 2).

Cortes, R., Probst, A., Tobler, H.J., Palacios, J.M., 1986. Muscarinic cholinergic receptor subtypes in the human brain: II. Quantitative autoradiographic studies. Brain Res. 362 (2), 239-253.

De Souza, E.B., Insel, T.R., Perrin, M.H., Rivier, J., Vale, W.W., Kuhar, M.J., 1985. Corticotropin-releasing factor receptors are widely distributed within the rat central nervous system: an autoradiographic study. J. Neurosci. 5 (12), 3189-3203.

Dockray, G.J., 2004. The expanding family of -Rfamide peptides and their effects on feeding behaviour. Exp. Physiol. 89.3, 229-235.

Fujii, M., 1982. Cyto- and myeloarchitectural studies on the lateral tuberal nucleus in simian Callithricidae and Prosimiae. Acta Anat. (Basel) 114 (2), 155-164.

Goncharuk, V., Yeng, Y., Wang, R., Mactavish, D., Jhamandas, J.H., 2004. Distribution of the neuropeptide FF1 receptor (hFF1) in the human hypothalamus and surrounding basal forebrain structures: immunohistochemical study. J. Comp. Neurol. 474 487-503.

Hardman, C.D., Henderson, J.M., Finkelstein, D.I., Horne, M.K., Paxinos, G., Halliday, G.M., 2002. Comparison of the basal ganglia in rats, marmosets, macaques, baboons and humans: volume and neuronal number for the output, internal relay, and striatal modulating nuclei. J. Comp. Neurol. 445, 238-255.

Hofman, M.A., 1997. Lifespan changes in the human hypothalamus. Exp. Gerontol. 32 (4-5), 559-575.

Kremer, H.P.H., 1992. The hypothalamic lateral tuberal nucleus: normal anatomy and changes in neurological diseases. Prog. Brain Res. 93, 249-261.

Kremer, H.P.H., Bots, G.Th.A.M., 1993. Lewy bodies in the lateral hypothalamus: do they imply neuronal loss? Mov. Disord. 8 (3), 315-320.

Kremer, H.P.H., Roos, R.A.C., Dingjan, G., Marani, E., Bots, G.Th.A.M., 1990. Atrophy of the hypothalamus lateral tuberal nucleus in Huntington's disease. J. Neuropathol. Exp. Neurol. 49, 371-382.

Kremer, H.P.H., Roos, R.A.C., Dingjan, G., Marani, E., Bots, G.Th.A.M., Bruyn, G.W., Hofman, M.A., 1991. The hypothalamic lateral tuberal nucleus and the characteristics of the neuronal loss in Huntington's disease. Neurosci. Lett. 132, 101-104.

Le Gros Clark, W.E., Beattie, J., Riddoch, G., Dott, N.M., 1938. The Hypothalamus: Morphological, Functional, Clinical and Surgical Aspects. The William Ramsay Henderson Trust, Edinburgh, pp. 64-68.

Millan, M.A., Jacobowitz, D.M., Hauger, R.L., Catt, K.J., Aguilera, G., 1986. Distribution of corticotropin-releasing factor receptors in primate brain. Proc. Natl. Acad. Sci. U. S. A. 83 (6), 1921-1925.

Morton, A.J., Wood, N.I., Hastings, M.H., Hurelbrink, C., Barker, R.A., Maywood, E.S., 2005. Disintegration of the sleep-wake cycle and circadian timing in Huntington's disease. J. Neurosci. 25 (1), 157-163.

Narkiewicy, O., Dyiewiatkowski, J., Morys, J., 1994. Lateral tuberal nucleus in man and macaca: comparative morphometric investigations. Folia Morphol. 53, 1-12.

Nicklous, D.M., Simansky, K.J., 2003. Neuropeptide FF exerts pro- and anti-opioid actions in the parabrachial nucleus to modulate food intake. Am. J. Physiol.: Regul., Integr. Comp. Physiol. 285, 1046-1054.

Pelletier, G., Desy, L., Cote, J., Vaudry, H., 1983. Immunocytochemical localization of corticotropin-releasing factor-like immunoreactivity in the human hypothalamus. Neurosci. Lett. 41 (3), 259-263.

Sakaue, M., Saito, N., Taniguchi, H., Baba, S., Tanaka, C., 1988. Immunohistochemical localization of gamma-aminobutyric acid in the rat pituitary gland and related hypothalamic regions. Brain Res. 446 (2), 343-353.

Schultz, C., Koppers, D., Sassin, I., Braak, E., Braak, H., 1998. Cytoskeletal alterations in the human tuberal hypothalamus related to argyrophilic grain disease. Acta Neuropathol. (Berl.) 96 (6), 596-602.

Tappaz, M.L., Brownstein, M.J., Kopin, I.J., 1977. Glutamate decarboxylase (GAD) and gamma-aminobutyric acid (GABA) in discrete nuclei of hypothalamus and substantia nigra. Brain Res. 125 (1), 109-121.

Timmers, H.J.L.M., Swaab, D.F., van de Nes, J.A.P., Kremer, H.P.H., 1996. Somatostatin 1-12 immunoreactivity is decreased in the hypothalamic lateral tuberal nucleus of Huntington's disease patients. Brain Res. 728, 141-148.

Trottier, S., Chotard, C., Traiffort, E., Unmehopa, U., Fisser, B., Swaab, D.F., Schwartz, J.C., 2002. Co-localization of histamine with GABA but not with galanin in the human tuberomamillary nucleus. Brain Res. 939 (1-2), 52-64. 